\title{
Influence of the underneath Cavity on Buoyant-forced Cooling of the Integrated Photovoltaic Panels in Building Roof: a Thermography Study
}

Parham A. Mirzaei ${ }^{1,2,3}$, Jan Carmeliet ${ }^{1,2}$

Laboratory for Building Science and Technology, Swiss Federal Laboratories for Materials Testing and Research (Empa), Überlandstrasse 129, 8600 Dübendorf, Switzerland 1

Swiss Federal Institute of Technology Zurich (ETHZ), Wolfgang-Pauli-Strasse 15, 8093 Zürich, Switzerland 2

The University of Nottingham, University Park, Nottingham, NG7 2RD, UK 3

\begin{abstract}
Air flow around building integrated photovoltaic (BIPV) has a significant impact on their hygrothermal behavior and degradation. The potential of reducing the temperature of BIPV using underneath cavity is experimentally and numerically investigated in literature. Most of the models are over-simplified in terms of modeling the impact of 3D flow over/underneath of PV modules, which can result in a non-uniform surface temperature and consequently a nonhomogenous thermal degradation. Moreover, the simultaneous presence of radiation and convection related to upstream wind, in addition to the combined impact of back-ventilation and surface convection, are barely addressed in literature. However, these simplifications can result in the unrealistic loading climate conditions.
\end{abstract}
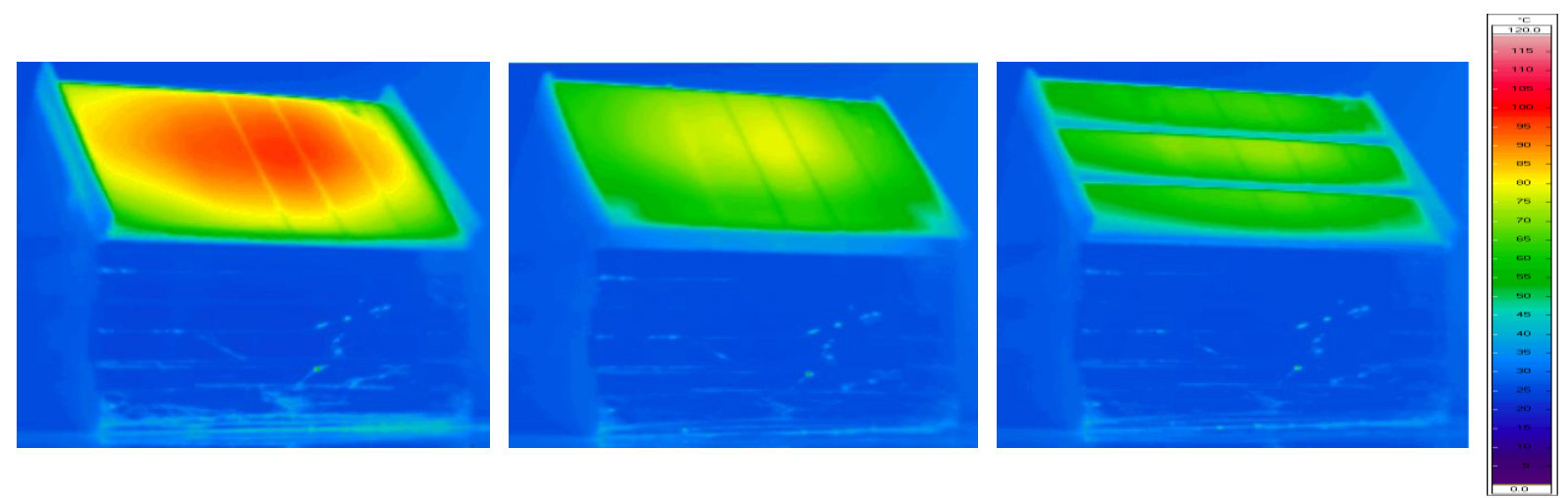

This paper aims to present a unique experimental setup in order to provide more realistic climate conditions for investigating the ventilation potential of the underneath. The setup consists of a solar simulator and a building prototype with installed PV, placed inside an atmospheric wind tunnel to control upstream wind velocity. Thermography is performed using an infra-red camera to monitor the surface temperature of the BIPV. The potential of underneath cavity with various cavity heights and PV arrangement is further investigated in 
this paper. The outcome would be eventually useful in development of practical guidelines for BIPV installation.

Keywords: Solar Energy, Photovoltaic Panel, Wind Tunnel, Building, Cavity

\section{Introduction}

The global energy demand from its current amount, 10 terawatts per year, is projected to increase $300 \%$ by 2050 (Razykov, et al., 2011). With the present drastic growth of urbanization (Mirzaei \& Haghighat, 2010), the energy demand is projected to severely increase in the near future. Among major sectors of energy consumption in developed countries, the building sector is responsible for consumption of $20-40 \%$ of the total final energy (Pérez-Lombard, Ortiz, \& Pout, 2008). Responding to this increasing energy demand and dealing with current issues regarding global warming, climate changes and $\mathrm{CO} 2$ emissions, the widespread implementation of renewable and clean types of energy in all energy consumption sectors including the building sector is required. In other words, it is not feasible to pursue the goal of Net-Zero-Energy buildings without the integration of the renewable energies in the building sector. Despite the extensive benefits of the renewable energies, current share of renewable energies in total primary energy of the world is about $13.3 \%$ (Hasan \& Sumathy, 2010). Among all sources of renewable energies, solar energy is known as the most abundant, inexhaustible, and clean form of energy (Petter Jelle, Breivik, \& Drolsum Røkenes, 2012). The intercepted energy from sun by earth is estimated about $1.8 \times 10^{11}$ MW (Parida, Iniyan, \& Goic, 2011). This implies that the energy provided by sun is 10,000 times the energy demand of planet.

Despite the above mentioned advantages and also the simplicity of using photovoltaics, solar energy is still the most expensive choice. At the moment, only $0.05 \%$ of the total primary energy is reported to be supplied by photovoltaic technologies (Solangi, Islam, Saidur, Rahim, \& Fayaz, 2011). However, a considerable demand and growth in using photovoltaic is projected. The development and installation of solar PV electricity in various countries is predicted to increase from 10,000 MW to 140,000 MW from 2010 to 2030 (Solangi, et al., 2011).

This excessive interest is also observed in the implementation of building integrated photovoltaics (BIPVs). Building integrated PVs in roof and façade solution and photovoltaic thermal hybrid solar collectors (PV/T) have been emerged as a mature technology which provides significant advantages on cost and appearance. PV/T consists of a solar collector and 
a PV module, and is classified to: liquid PV/T collectors, air PV/T, ventilated PV with heat recovery, and PV/T concentrators. Advantage of $\mathrm{PV} / \mathrm{T}$ is mainly reported in considerable thermal-electrical efficiency increase of PV technology from 4-20\% to almost $60 \%$ while PV/T is claimed to be also a cheaper technology in terms of energy production (Chow, 2010).

The crystalline silicon (c-Si) based PVs are a highly preferable option and at the moment about $90 \%$ of total PV market is reported to be c-Si based (Kumar \& Rosen, 2011). The main drawback with c-Si PV modules is their temperature-dependent efficiency as it is inversely proportional to temperature. This implies that the efficiency will fall below the rated efficiency provided by the module manufacturer at temperatures above $25{ }^{\circ} \mathrm{C}$. Many correlations are provided in literature to predict this loss, e.g., a $0.4 \%-0.65 / \mathrm{K}$ as reported by (Hasan \& Sumathy, 2010; Kumar \& Rosen, 2011). Moreover, increased surface temperatures of building envelopes can have environmental impacts such as the creation of urban heat island (Scherba, Sailor, Rosenstiel, \& Wamser, 2011). Furthermore, undesired high surface temperatures on their variation in time result in degradation due to thermal stresses (Chow, 2010). One can add the impact of moisture ingress in the degradation of PV modules mainly at the cell interconnections and/or in cracked cells.

Back-ventilation or inducing airflow underneath the cavity of the PV modules is proposed as an effective strategy in order to reduce their surface temperatures. Computational fluid dynamics (CFD) has been used as a powerful tool to study the cavity ventilation potential (Gan, 2009; Corbin \& Zhai, 2010; Yoo \& Manz, 2011). Mei et al. (2009) performed an experiment to test PV modules under various climate conditions. Back ventilation was performed by installing a fan behind the cavity while different ventilation rates were applied.

However, in the above mentioned investigations, the simultaneous effect of airflow above and underneath the cavity was barely considered while in reality a part of the airflow passes over the PV modules and a part flushes the underneath cavity. Therefore, this study intends to understand the impact of simultaneous flow above and underneath of the PV modules. For this purpose, a unique experimental setup is developed. Employing a thermography technique, the aim of this setup is to monitor the surface temperature of PV modules in presence or absence of an underneath cavity exposed to various upstream wind velocities and radiation intensities. The result of this study in addition with the future development of a simulation model, and the experiment of the air speed with particle image velocimetry (PIV) technique will result in development of recommendations and guidelines for the installation of roof and 
façade integrated PV modules, e.g. for promoting cavity ventilation in order to reduce the hygrothermal loading of the PV modules.

\section{Experimental Setup}

As discussed earlier, the main objective of this experiment is to understand the potential of underneath cavity ventilation for cooling the PV modules. It is important to induce a radiation flux on the PV module using convective cooling by air which flushes the underneath cavity and flows above the PV's surface. Figures 1 and 2 depict the unique setup of the developed experiment, including building prototype, radiation source (solar simulator), and monitoring devices (i.e. infrared camera, thermocouples, and thermopiles). The whole setup is placed inside the ETH/Empa wind tunnel; the test section of this tunnel is $1300 \mathrm{~mm}$ in height and $1900 \mathrm{~mm}$ in width.

The building prototype consists of an insulated Styrofoam structure. The roof is covered with photovoltaic modules. The cavity height can be adjusted as well as type: flat and stepped installation (see Fig. 1c and 1d). The roof inclination is $45^{\circ}$. The building height from floor to highest point of the roof is $582.8 \mathrm{~mm}$, while the height of walls is $300 \mathrm{~mm}$. The solar simulator includes a $2 \times 3$ array of $250 \mathrm{~W}$ infrared lamps (Fig. 2b). The solar simulator is connected to an adjustable power system to provide different heat flux values. The distance between solar simulator and PV surface is $800 \mathrm{~mm}$. As shown in Figure 1a, an infrared camera (IRC) has been installed far away from the prototype and close to the wall of wind tunnel in order to monitor the surface temperature of the PV modules. A surface thermocouple has been attached on the PV surface to calibrate the IRC pictures (see Fig. 2c). This technique is further explained in the following sections.

As it can be seen in Figure 2c, the installed thermopile measures the exact amount of incident radiation to the PV surface. It is noteworthy to mention that the incident radiation in a fixed voltage supplied to the infrared lamps significantly varies due to the different convective fluxes using different upstream velocities. Therefore, the implementation of a thermopile is crucial to control the radiation intensity from the infrared lamps to the PV surface. The uniformity of the radiation intensity on the PV surface has been monitored by placing the thermopile at various points.

Aluminum sheets and tape have been placed on the building windward wall and the floor close to it in order to reflect the radiation and avoid a temperature increase of these surfaces 
(see Fig. 2a). The upstream flow is not been affected by any other surfaces except the building unit. The performance of this technique has been ensured by IRC observation as the temperature of windward wall and neighboring floor was almost equal to the airflow temperature.

As illustrated in Figure 1c, eight thermocouples in two arrays of four have been attached on the cavity surfaces of the underneath building's roof structure (T1 to T4) and of the PV (T5 to T8). The array of thermocouples was placed $180 \mathrm{~mm}$ from left side of the roof. The distance of thermocouples T1, T2, T3, and T4 from highest point of the roof is $10 \mathrm{~mm}, 140 \mathrm{~mm}, 270 \mathrm{~mm}$, and $390 \mathrm{~mm}$, respectively.

\subsection{Measurement Scenarios}

To investigate the influence of the underneath cavity on the cooling of the PV modules, four main scenarios were defined to understand the impact of underneath cavity, its height, and shape on the temperature of the PV modules. These scenarios include, (1) flat PV without underneath cavity, (2) flat PV with underneath cavity with a height of $10 \mathrm{~mm}, 20 \mathrm{~mm}$, and 30mm, (3) stepped PV without underneath cavity, and (4) stepped PV with underneath cavity. In the earlier case, three gaps between three PVs are $10 \mathrm{~mm}$ and the outlet height is $30 \mathrm{~mm}$ (see Fig. 1b and 1d). Each case was studied under three wind velocities (i.e. $0.5 \mathrm{~m} / \mathrm{s}, 1 \mathrm{~m} / \mathrm{s}, 2$ $\mathrm{m} / \mathrm{s}$ ) and three radiation intensities (i.e. $50 \frac{\mathrm{W}}{\mathrm{m}^{2}}, 100 \frac{\mathrm{W}}{\mathrm{m}^{2}}, 200 \frac{\mathrm{W}}{\mathrm{m}^{2}}$ ). The air temperature and relative humidity are respectively kept about $24.5 \mp 0.5^{\circ} \mathrm{C}$ and $33 \mp 1 \%$.

\subsection{Infrared Camera calibration}

The emissivity of PV modules varies with the surface temperature. The following correction procedure has been applied to ensure the accuracy of the obtained images from IRC. The recorded temperature at a certain point on the PV (see Fig. 2c) was compared to the temperature observed by IRC at the same point. Then, the emissivity of the image was adjusted until reaching similar temperatures for both IRC and thermocouple. The whole image was automatically adjusted by the software according to the new emissivity using the StefanBoltzmann equation. As demonstrated in Figure 3, the results of different scenarios show that the emissivity fluctuates between 0.87 and 0.93 according to the temperature of the PV surface. The average emissivity is 0.90 .

\subsection{Thermocouples and Thermopiles Calibration}


The common ice-bath technique was employed to calibrate the thermocouples. In this technique the T-type thermocouples were floated within a mixture of ice and water for a long period of time to reach $0{ }^{\circ} \mathrm{C}$ temperature. The accuracy of thermocouples is $\pm 0.3^{\circ} \mathrm{C}$.

A setup has been also developed to calibrate the output voltage from thermopiles. The incident irradiation on a circular black painted plate (to represent a black body) at specific distance has been measured with the thermopile. The generated voltage from thermopile is multiplied by responsivity, a constant number, which allows converting the irradiation in flux (watt). The distance between the thermopile and the plate is $100 \mathrm{~mm}$. The diameter of plate is $100 \mathrm{~mm}$. The view factor associated to the incident radiation from the circular plate to the thermopile can be analytically calculated as $\mathrm{F}=(\sin \alpha)^{2}$, where $\alpha$ is the angle between the thermopile and the black plate. The radiation flux (q) is then given by Stefan-Boltzman equation:

$q=F A_{s} \varepsilon \sigma\left(T_{P}^{4}-T_{s}^{4}\right)$

where $\sigma=5.67 \times 10^{-8}$ is Stefan-Boltzman constant, $\mathrm{A}_{\mathrm{s}}=0.00785 \mathrm{~m}^{2}$ is the area of the black plate, $\varepsilon$ is the emissivity of black plate (here assumed $\varepsilon=1$ ), $\mathrm{T}_{\mathrm{p}}$ is the plate temperature, and $\mathrm{T}_{\mathrm{S}}$ is the thermopile temperature.

The incident radiation values on the PV surface measured by the thermopile (Dexter Company) and calculated by eq. 1, are compared obtaining the responsivity. Figure 4 depicts the responsivity constant. The maximum and minimum range as given by producer is also shown in Figure 5. However, the typical suggested responsivity is 97.7 as obtained in the measurements. The test has been repeated several times and the same result has been observed after reaching a stable situation (2-3 minutes) for the thermopile. Therefore, the numbers suggested by company are used for the experiment.

\subsection{Uniformity Test}

Prior to the experiments, a uniformity test for the radiation intensity was performed. The conclusion was that the radiation intensities vary up to $15 \%$ in different points of the PV modules. The radiation was more intense at middle and less intense at corners due to the superposition of IR lamps. However, the obtained range of uniformity was assumed to be acceptable since this study had a comparison format and similar radiation intensity was emitted in all scenarios. Moreover, the measured temperature distribution can be simulated with the current profile to validate the future numerical models. 
An anemometer was used to measure the upstream velocity of the wind tunnel at three meters from a same height as windward wall of building prototype $(300 \mathrm{~mm})$. Each experiment case was employed until steady-state situation was reached. This means that after a certain time, and under constant wind velocity and radiation intensity, the temperature of PV modules measured by IRC and thermocouples did not significantly fluctuate anywhere. A considerable change in the airflow temperature has not been also monitored during the experiments.

\section{Results and Discussion}

\subsection{Impact of underneath the cavity and height}

Figures 6 through 8 illustrate the temperature on the surface of the PV module under various upstream velocities and radiation intensities. Mean and maximum surface temperatures of the PV module are shown in Table 1 and 2, respectively. Each upstream velocity and radiation intensity is defined as a specific case study. The highest temperature difference on the surface is also provided in these tables. The reason for this selection of velocities and intensities was to cover a range of flow in which both natural and forced convections are contributing. In this study, the corresponding number to present the impact of buoyant/forced flow is the bulkRichardson number $(\mathrm{Rb})$ :

$R b=\frac{g L \beta\left(T_{P V b}-T_{a}\right)}{U_{a}^{2}}$

where $g$ denotes the gravity acceleration, $\beta$ is the thermal expansion of air at inflow temperature, $\mathrm{L}$ represent the length of $\mathrm{PV}, T_{P V b}$ is the bulk surface temperature of the $\mathrm{PV}$ module, $U_{a}$ and $T_{a}$ are the upstream velocity and temperature, respectively.

Using $T_{P V b}$ from Table 1 in Eq. 2 , it is found that $\mathrm{Rb}$ varies from $\mathrm{Rb}=0.016\left(\mathrm{RI}=50 \frac{\mathrm{W}}{\mathrm{m}^{2}}, U_{a}=2\right.$ $\mathrm{m} / \mathrm{s})$ to $\mathrm{Rb}=3.051\left(\mathrm{RI}=200 \frac{W}{m^{2}}, U_{a}=0.5 \mathrm{~m} / \mathrm{s}\right)$. In Figure 5 , the bulk-Richardson number is plotted versus Reynolds number for different radiation intensities and upstream wind velocities.

Figures $6 \mathrm{a}-8 \mathrm{a}, 6 \mathrm{~g}-8 \mathrm{~g}$, and $6 \mathrm{~m}-8 \mathrm{~m}$ show the surface temperature of the PV module when the underneath cavities are closed. In these cases, the flow above the PV surface is the only way of convective heat exchange. As it is presented in Table 1, the highest PV surface temperature $\left(T_{P V b}=83.3^{\circ} \mathrm{C}\right)$ occurs for the higher radiation $\mathrm{RI}=200 \frac{\mathrm{W}}{\mathrm{m}^{2}}$ and lower air speed $U_{a}=0.5 \mathrm{~m} / \mathrm{s}$. Under constant $\mathrm{RI}$, the $\mathrm{T}_{\mathrm{PVb}}$ tends to decrease for higher upstream velocities as the forced 
convection is considerably increased, e.g. $T_{P V b}$ is $74.2^{\circ} \mathrm{C}$ and $60^{\circ} \mathrm{C}$ in $U_{a}=1.0 \mathrm{~m} / \mathrm{s}$ and $U_{a}=2.0$ $\mathrm{m} / \mathrm{s}$, respectively. Surprisingly, a separated hot region from the main elliptical region can be observed in lower part of the PV module for the higher velocities (see Fig. 6a, 6g, and 6m). However, for the lower velocities this region is smoothly mixed with the main region. The reason could be related to the fact that the flow separates from the edge of the PV module. Moreover, corner eddies may contribute to non-uniform temperatures on the PV surface. A similar phenomenon also can be observed for higher radiation intensities (see Fig. 7a-8a, 7g$8 \mathrm{~g}$, and $7 \mathrm{~m}-8 \mathrm{~m}$ ) where the mean and maximum temperature increases.

Figures $6 \mathrm{~b}-6 \mathrm{~d}, 6 \mathrm{~h}-6 \mathrm{j}$, and $6 \mathrm{n}-6 \mathrm{p}$ demonstrate the impact of underneath cavity height with $\mathrm{RI}=50 \frac{W}{m^{2}}$ for $U_{a}=2.0, U_{a}=1.0$, and $U_{a}=0.5$, respectively. The heat removal from the PV module is increased from the backside as airflow penetrates the cavity. When the cavity height is $10 \mathrm{~mm}$, the mean surface temperature of the PV is respectively reduced by $3.9{ }^{\circ} \mathrm{C}$, $4.6{ }^{\circ} \mathrm{C}$, and $6.6{ }^{\circ} \mathrm{C}$ for $U_{a}=2.0, U_{a}=1.0$, and $U_{a}=0.5$ (see Table 1 and 2), while the maximum surface temperature is decreased by $5^{\circ} \mathrm{C}, 5.7^{\circ} \mathrm{C}$, and $8.3^{\circ} \mathrm{C}$. As discussed earlier, the reduction of the maximum temperature is an essential factor related to an increase of the durability of PV modules. Only a slight change of mean and maximum temperature at lower velocities can be observed when the cavity height is increased to $20 \mathrm{~mm}$. This implies that for our study increasing the cavity height more than $20 \mathrm{~mm}$ does not have a further influence on cooling of the PV module. This observation is almost valid for all other radiation intensities, and implies the existence of an optimum size for the cavity height for the flat installation of the PV modules.

\subsection{Impact of PV installation arrangement}

To show the importance of PV arrangement, three PV modules $(580 \mathrm{~mm} \times 100 \mathrm{~mm})$ were placed in a stepped arrangement according to Figure $1 \mathrm{~b}$ and $1 \mathrm{~d}$ where the size of the cavity inlet beneath each PV module was set to $10 \mathrm{~mm}$. Similar to the previous section, the test was repeated for three air velocities and three radiation intensities. Also, the experiment was repeated for open-cavity and closed-cavity situations.

Figures 6e-6f, 6k-61, 6q-6r through 8e-8f, 8k-81, 8q-8r clearly shows the considerable change in surface temperature of PV modules when the underneath cavity is open. The mean and maximum temperatures are given in Table 1 and 2. For example, the difference of mean surface temperature between closed-cavity and open-cavity cases exceeds $26.8{ }^{\circ} \mathrm{C}$ when 
$\mathrm{RI}=200 \frac{\mathrm{W}}{\mathrm{m}^{2}}$ and $U_{a}=0.5$. Surprisingly, the lowest mean of maximum surface temperatures for all cases occur for the stepped arrangement of the PV modules.

This observation can be explained by the fact that more air will penetrate through the three inlets compared to the case where only air flushes through the single inlet in the flat setup. This means that the shorter length of PV modules in the stepped configuration helps to exchange more fresh air from above, resulting in a lower temperature increase of the PV modules. One should also mention that the stepped arrangement causes more turbulence flow around the PVs which results in higher convective heat exchanges at the PV surfaces.

From Figures 6 through 8 it is found that the middle of these PV modules has the highest temperature in all cases. The highest temperature occurs in a half-ellipse hot region and it is more intensified for closed-cavity cases. The half-ellipse hot region also exists in upper and lower PV modules with almost the same intensity in open-cavity cases. However, the halfellipse hot region tends to be more slender for higher upstream velocity. In closed-cavity cases and in higher upstream velocities, the half-ellipse hot region in lower PV tends to be slender similar to the flat cases.

On the other hand, the surface temperature of the upper PV module is considerably cooled for higher velocities. In general, it can be concluded that the temperature of the PVs is slightly affected by the 3D flow regime containing complex eddies imposed from edges and corner of the PV modules.

\subsection{Underneath temperatures}

In this section, the potential of airflow for removing heat within cavity is investigated in more detail. In addition to surface temperature thermography of the PV modules, the cavity temperature is measured using eight thermocouples as shown in Figure 1c. As illustrated in Figure 9, the temperature at the back side of the flat PV continues to increase close to the cavity outlet where it is slightly decreased, which is similar to the results obtained from the thermography figures. The temperature difference between PV-side and roof-side is higher close to the middle and lower at the inlet and outlet of the cavity (see Fig. 9). Although larger cavity heights result in lower temperatures, the temperature difference between PV-side and roof-side is almost the same for all cavity sizes. It should be emphasized that the enlargement of cavity height does not significantly reduce the PV-side and roof-side temperatures for 
cavity heights greater than $20 \mathrm{~mm}$. This observation result has been also more observed in the previous section.

Evidently, the surface temperature at both PV-side and roof-side are reduced with increasing upstream velocity. This implies that in the higher upstream velocities the impact of cavity height is less important, while it is inversely more important at the lower upstream velocities. Calculation of bulk-Richardson number $\left(R_{b}=\frac{g L\left(T_{m e a n}-T_{a}\right)}{\beta U_{a}^{2}}\right)$ for different upstream velocities confirms the mentioned results as it varies between $0.05<\mathrm{Rb}<0.09,0.32<\mathrm{Rb}<0.64$, and $1.64<\mathrm{Rb}<3.05$ for $U_{a}=2.0 \mathrm{~m} / \mathrm{s}, U_{a}=1.0 \mathrm{~m} / \mathrm{s}, U_{a}=0.5 \mathrm{~m} / \mathrm{s}$, respectively. $T_{a}$ and $U_{a}$ are the air temperature and velocity at upstream, $T_{\text {mean }}$ is the mean temperature of the $\mathrm{PV}, \mathrm{L}$ is the length of the $\mathrm{PV}, \mathrm{g}$ is the gravity acceleration, and $\beta$ is the thermal expansion coefficient for the air.

The temperature pattern is significantly different for the stepped PV arrangement. In general and regardless of the upstream velocity and the cavity height, PV-side and roof-side temperatures are in the lowest range, specifically in the roof-side. This means that the stepped arrangement is much more capable of removing heat not only from the PV-side, but also from the roof-side when comparing to the flat arrangement.

\section{Conclusion}

An experimental setup is developed to provide more realistic climate condition for a BIPV (building integrated photovoltaic) prototype. The setup includes a solar simulator which is positioned in an atmospheric wind tunnel in order to provide a range of various radiation intensities over the BIPV. The approaching upstream wind is controlled in the wind tunnel. The temperatures within the underneath cavity and at the front side of the PV module are monitored with thermocouples and IR camera, respectively. To emit the desired radiation intensity a control is developed using a thermopile on the PV surface.

The measurement is repeated under various upstream velocities, radiation intensities, and cavity sizes and arrangements. Main results can be summarized as follows:

- Higher ventilation can be achieved using stepped PV arrangements with open cavity behind the modules compared to a flat arrangement.

- 3D flow (e.g. lateral eddies) contributes in a non-uniform surface temperature distribution over the PV modules.

- Influence of the cavity height is significantly greater for higher upstream velocities. 
Future research will be performed to visualize the flow underneath and above the cavity using PIV technique. The results will be used to validate a 3D CFD model for simulating the annual variation of temperatures of the PV modules. These data can be later used for the development of tools for prediction of PV degradation probability in various climates, or for defining accelerated aging test conditions for enhancing the durability of the PV modules.

\section{Acknowledgement}

The authors would like to express their gratitude to Swiss-electric Research (SER), the Competence Center energy and Mobility (CCEM), the Swiss federal Office for Energy (SFOE) and the Services Industriels Genevois (SIG) for financing the ARCHINSOLAR project. Also, the financial support by Marie Curie COFUND project, Swiss Federal Laboratories for Materials Testing and Research (Empa), and ETH University are gratefully acknowledged.

\section{References}

Chow, T. T. (2010). A review on photovoltaic/thermal hybrid solar technology. Applied Energy, 87(2), 365-379.

Corbin, C. D., \& Zhai, Z. J. (2010). Experimental and numerical investigation on thermal and electrical performance of a building integrated photovoltaic-thermal collector system. Energy and Buildings, 42(1), 76-82.

Gan, G. (2009). Effect of air gap on the performance of building-integrated photovoltaics. Energy, 34(7), 913-921.

Hasan, M. A., \& Sumathy, K. (2010). Photovoltaic thermal module concepts and their performance analysis: A review. Renewable and Sustainable Energy Reviews, 14(7), 1845-1859.

Kumar, R., \& Rosen, M. A. (2011). A critical review of photovoltaic-thermal solar collectors for air heating. Applied Energy, 88(11), 3603-3614.

Mei, L., Infield, D. G., Gottschalg, R., Loveday, D. L., Davies, D., \& Berry, M. (2009). Equilibrium thermal characteristics of a building integrated photovoltaic tiled roof. Solar Energy, 83(10), 1893-1901.

Mirzaei, P. A., \& Haghighat, F. (2010). Approaches to study Urban Heat Island - Abilities and limitations. [doi: DOI: 10.1016/j.buildenv.2010.04.001]. Building and Environment, 45(10), 2192-2201.

Parida, B., Iniyan, S., \& Goic, R. (2011). A review of solar photovoltaic technologies. Renewable and Sustainable Energy Reviews, 15(3), 1625-1636.

Pérez-Lombard, L., Ortiz, J., \& Pout, C. (2008). A review on buildings energy consumption information. Energy and Buildings, 40(3), 394-398. 
Petter Jelle, B., Breivik, C., \& Drolsum Røkenes, H. (2012). Building integrated photovoltaic products: A state-of-the-art review and future research opportunities. Solar Energy Materials and Solar Cells, 100(0), 69-96.

Razykov, T. M., Ferekides, C. S., Morel, D., Stefanakos, E., Ullal, H. S., \& Upadhyaya, H. M. (2011). Solar photovoltaic electricity: Current status and future prospects. Solar Energy, 85(8), $1580-$ 1608.

Scherba, A., Sailor, D. J., Rosenstiel, T. N., \& Wamser, C. C. (2011). Modeling impacts of roof reflectivity, integrated photovoltaic panels and green roof systems on sensible heat flux into the urban environment. Building and Environment, 46(12), 2542-2551.

Solangi, K. H., Islam, M. R., Saidur, R., Rahim, N. A., \& Fayaz, H. (2011). A review on global solar energy policy. Renewable and Sustainable Energy Reviews, 15(4), 2149-2163.

Yoo, S.-H., \& Manz, H. (2011). Available remodeling simulation for a BIPV as a shading device. Solar Energy Materials and Solar Cells, 95(1), 394-397. 
Table 1. The mean surface temperature of the PV module under various upstream velocities and radiation intensities

\begin{tabular}{|c|c|c|c|c|c|c|c|}
\hline \multicolumn{7}{|c|}{ Mean Temperature of the PV Surface $\left({ }^{\circ} \mathrm{C}\right)$} & \multirow{3}{*}{$\begin{array}{l}\text { Largest } \\
\Delta \mathrm{T}\left({ }^{\circ} \mathrm{C}\right)\end{array}$} \\
\hline \multirow[t]{2}{*}{ Case } & \multicolumn{4}{|c|}{ Flat PV } & \multicolumn{2}{|l|}{ Stepped PV } & \\
\hline & Without gap & Gap $=10 \mathrm{~mm}$ & Gap=20mm & Gap=30mm & Without gap & Gap $=10 \mathrm{~mm}$ & \\
\hline $1 U_{a}=2.0 \mathrm{~m} / \mathrm{s}-\mathrm{RI}=50 \frac{\mathrm{W}}{\mathrm{m}^{2}}$ & 35.9 & 32.0 & 32.0 & 32.1 & 33.8 & 29.8 & 6.1 \\
\hline $2 U_{a}=1.0 \mathrm{~m} / \mathrm{s}-\mathrm{RI}=50 \frac{\mathrm{W}}{\mathrm{m}^{2}}$ & 41.9 & 37.3 & 35.7 & 35.6 & 38 & 32.6 & 9.3 \\
\hline $3 U_{a}=0.5 \mathrm{~m} / \mathrm{s}-\mathrm{RI}=50 \frac{\mathrm{m}^{2}}{\mathrm{~m}^{2}}$ & 46.4 & 39.8 & 38.4 & 38.6 & 44.5 & 35.2 & 11.2 \\
\hline $4 U_{a}=2.0 \mathrm{~m} / \mathrm{s}-\mathrm{RI}=100 \frac{\mathrm{W}}{\mathrm{m}^{2}}$ & 45.3 & 40.4 & 38.2 & 38.2 & 41.9 & 33.7 & 11.6 \\
\hline $5 \quad U_{a}=1.0 \mathrm{~m} / \mathrm{s}-\mathrm{RI}=100 \frac{\mathrm{W}}{\mathrm{m}^{2}}$ & 54.7 & 47 & 45 & 44.3 & 50.6 & 38.7 & 16.0 \\
\hline $6 \quad U_{a}=0.5 \mathrm{~m} / \mathrm{s}-\mathrm{RI}=100 \frac{\mathrm{m}^{2}}{\mathrm{~m}^{2}}$ & 60.1 & 52.7 & 49.5 & 49.9 & 60.3 & 42.7 & 17.6 \\
\hline $7 U_{a}=2.0 \mathrm{~m} / \mathrm{s}-\mathrm{RI}=200 \frac{\mathrm{W}}{\mathrm{m}^{2}}$ & 60.0 & 52.5 & 48.9 & 48.4 & 53.3 & 41.4 & 18.6 \\
\hline $8 U_{a}=1.0 \mathrm{~m} / \mathrm{s}-\mathrm{RI}=200 \frac{\mathrm{W}}{\mathrm{m}^{2}}$ & 74.2 & 62.7 & 59.8 & 58.1 & 68.8 & 49.9 & 24.3 \\
\hline $9 U_{a}=0.5 \mathrm{~m} / \mathrm{s}-\mathrm{RI} .=200 \frac{\mathrm{W}}{\mathrm{m}^{2}}$ & 83.3 & 71.7 & 66.5 & 65.8 & 83.8 & 57 & 26.8 \\
\hline
\end{tabular}

Table 2. The maximum surface temperature of the PV module under various upstream velocities and radiation intensities

\begin{tabular}{|c|c|c|c|c|c|c|c|}
\hline \multicolumn{7}{|c|}{ Maximum Temperature of the PV Surface $\left({ }^{\circ} \mathbf{C}\right)$} & \multirow{3}{*}{$\begin{array}{r}\text { Largest } \\
\Delta \mathrm{T}\left({ }^{\circ} \mathrm{C}\right)\end{array}$} \\
\hline \multirow{2}{*}{ Case } & \multicolumn{4}{|c|}{ Flat PV } & \multicolumn{2}{|l|}{ Stepped PV } & \\
\hline & Without gap & Gap $=10 \mathrm{~mm}$ & Gap=20mm & Gap $=30 \mathrm{~mm}$ & Without gap & Gap $=10 \mathrm{~mm}$ & \\
\hline $1 U_{a}=2.0 \mathrm{~m} / \mathrm{s}-\mathrm{RI}=50 \frac{\mathrm{W}}{\mathrm{m}^{2}}$ & 39.8 & 34.8 & 35 & 34.9 & 40.1 & 32.5 & 7.6 \\
\hline $2 U_{a}=1.0 \mathrm{~m} / \mathrm{s}-\mathrm{RI}=50 \frac{\mathrm{m}^{2}}{\mathrm{w}^{2}}$ & 46.7 & 41.0 & 40 & 39.3 & 44.2 & 36.5 & 10.2 \\
\hline $3 \quad U_{a}=0.5 \mathrm{~m} / \mathrm{s}-\mathrm{RI}=50 \frac{\mathrm{m}^{2}}{\mathrm{~m}^{2}}$ & 52.6 & 44.3 & 43.5 & 43.2 & 52.7 & 40.8 & 11.9 \\
\hline $4 U_{a}=2.0 \mathrm{~m} / \mathrm{s}-\mathrm{RI}=100 \frac{\mathrm{m}^{2}}{\mathrm{~m}^{2}}$ & 52.7 & 45.4 & 43.4 & 43 & 53.1 & 38.9 & 14.2 \\
\hline $5 \quad U_{a}=1.0 \mathrm{~m} / \mathrm{s}-\mathrm{RI}=100 \frac{\mathrm{m}^{2}}{\mathrm{~m}^{2}}$ & 64.7 & 54.3 & 52.9 & 51.4 & 61.7 & 46.5 & 18.2 \\
\hline $6 U_{a}=0.5 \mathrm{~m} / \mathrm{s}-\mathrm{RI}=100 \frac{\mathrm{W}}{\mathrm{m}^{2}}$ & 69.6 & 61.1 & 58.2 & 58.7 & 74.1 & 53.1 & 21.0 \\
\hline $7 U_{a}=2.0 \mathrm{~m} / \mathrm{s}-\mathrm{RI}=200 \frac{\mathrm{m}^{2}}{\mathrm{~m}^{2}}$ & 71.9 & 61.6 & 58.2 & 56.9 & 70.4 & 50.8 & 21.1 \\
\hline $8 U_{a}=1.0 \mathrm{~m} / \mathrm{s}-\mathrm{RI}=200 \frac{\mathrm{m}^{2}}{\frac{W}{2}}$ & 87.6 & 74 & 72.4 & 69.5 & 87.2 & 62.5 & 25.1 \\
\hline $9 U_{a}=0.5 \mathrm{~m} / \mathrm{s}-\mathrm{RI} .=200 \frac{\mathrm{m}^{2}}{\mathrm{~m}^{2}}$ & 97.7 & 84.7 & 80.4 & 78.9 & 104.8 & 72.8 & 32.0 \\
\hline
\end{tabular}




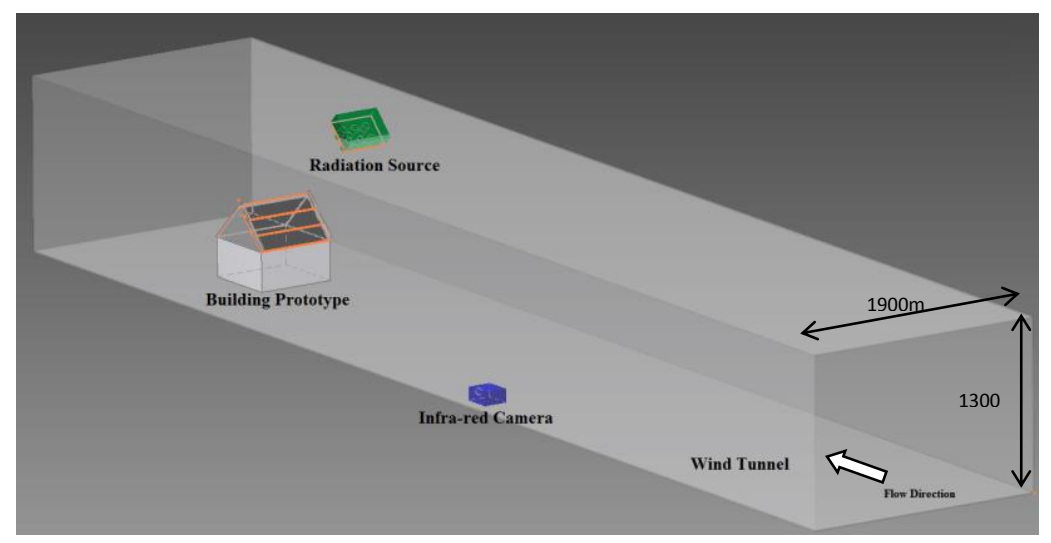

(a)

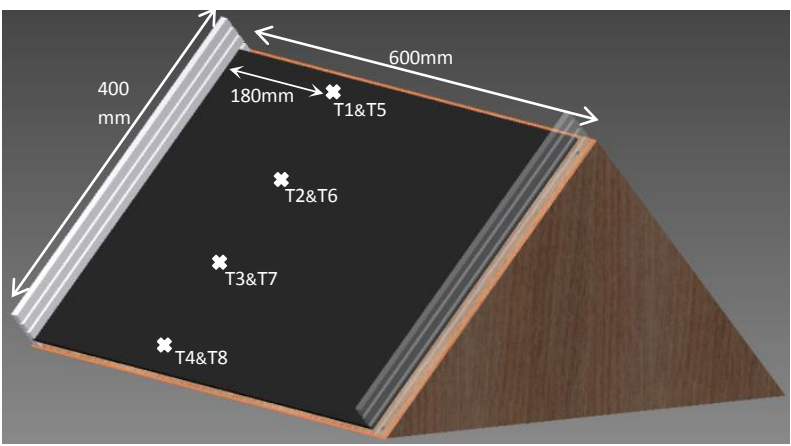

(c)

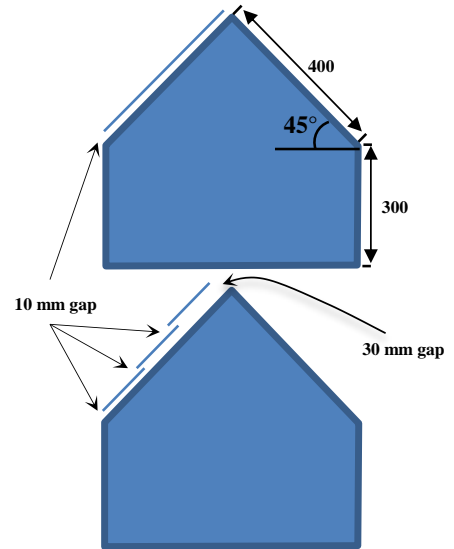

(b)

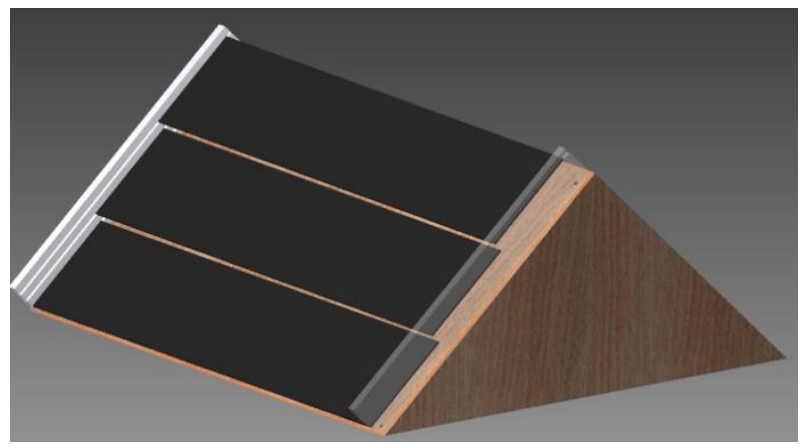

(d)

Figure 1. (a) Sketch of experiment setup (b) side views (c) flat PV - one 590mm×390mm PV module (d) stepped PV - three 590mm×130mm PV modules 


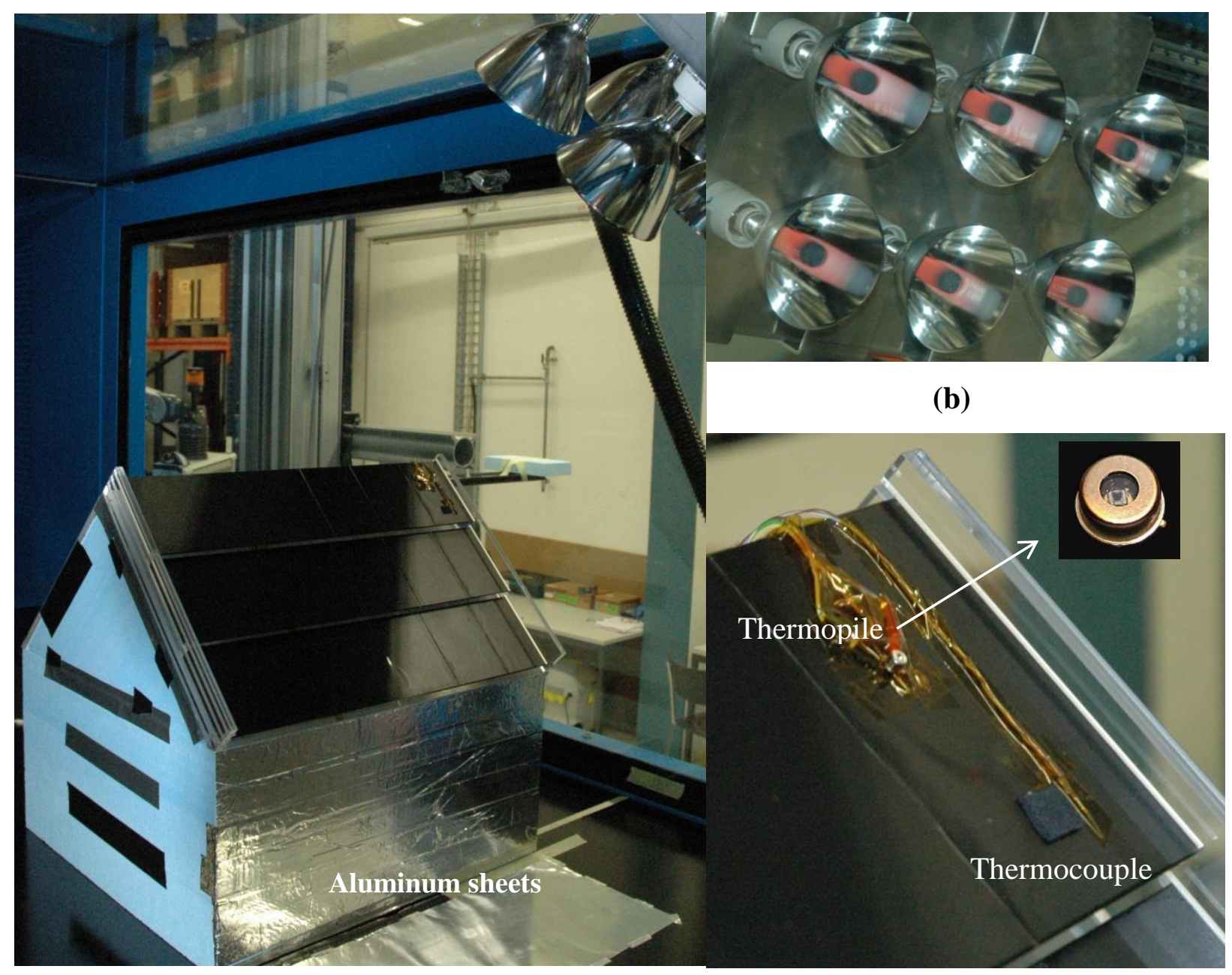

(a)

(c)

Figure 2. (a) Building prototype (b) infrared radiation source (solar simulator) (c) surface thermopile and thermocouple

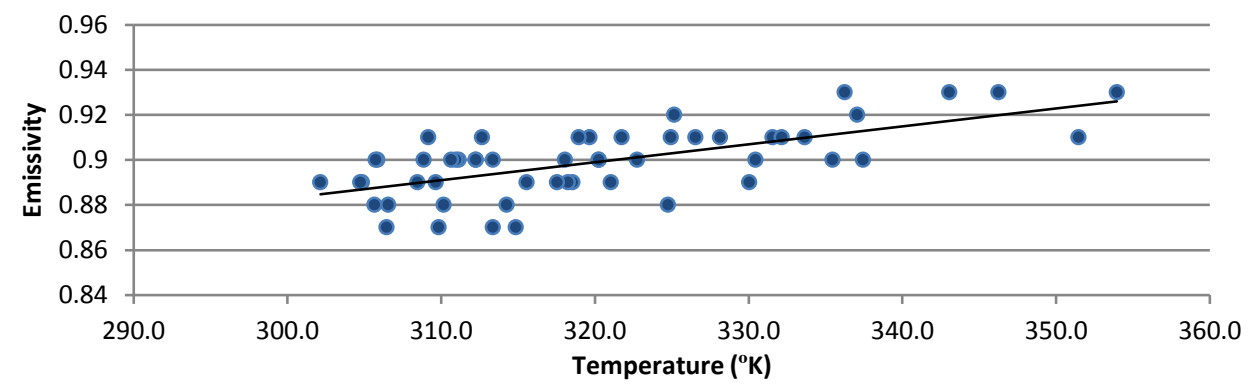

Figure 3. Emissivity of PV modules in different temperatures 


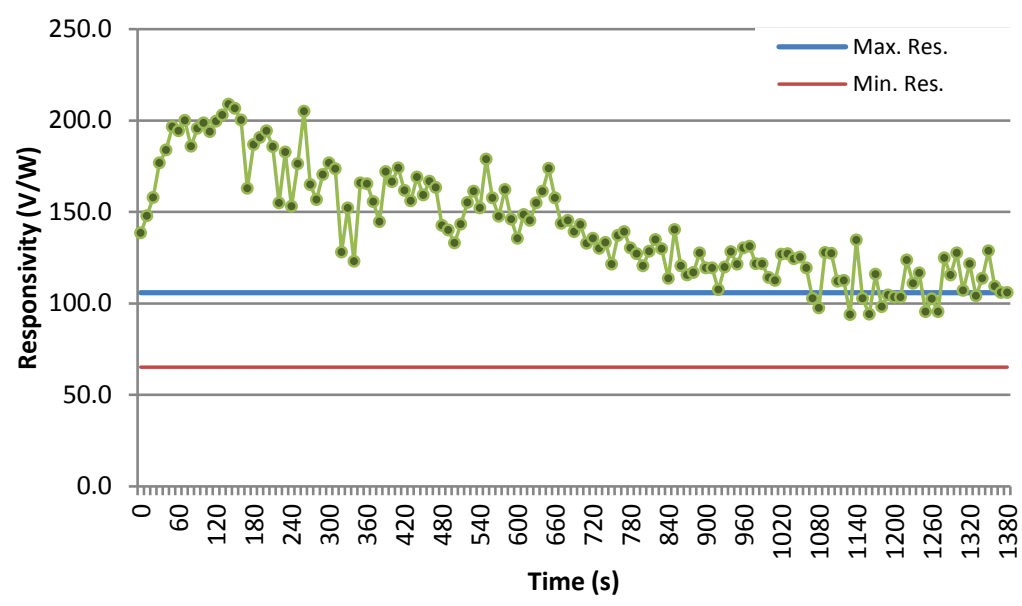

Figure 4. Responsivity calibration of thermopile constant

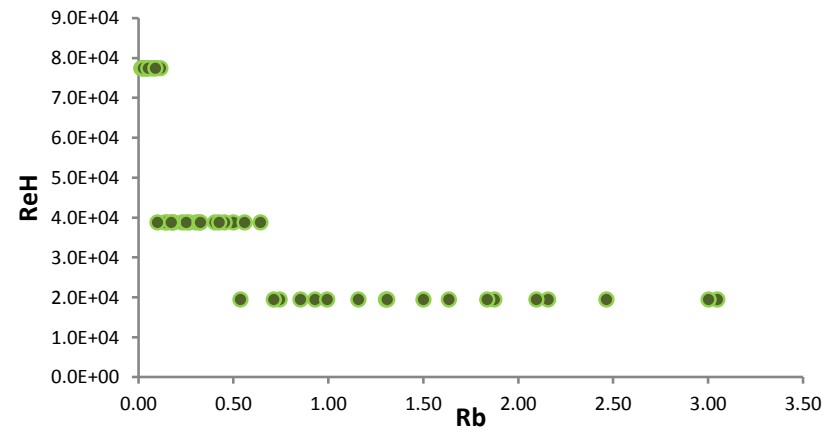

Figure 5. Reynolds number (for the height of prototype) versus bulk-Richardson number in different radiation intensities and upstream winds 


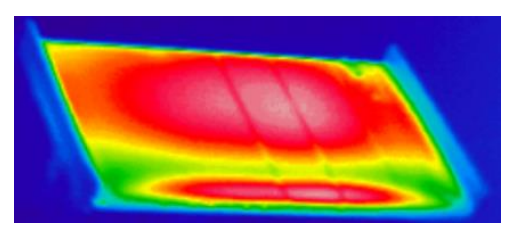

(a) Flat PV- without gap

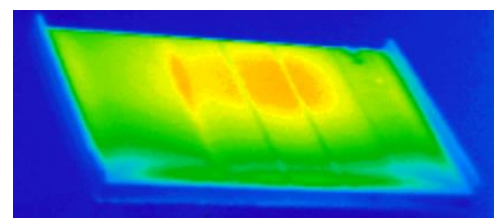

(c) Flat PV- gap $=20 \mathrm{~mm}$

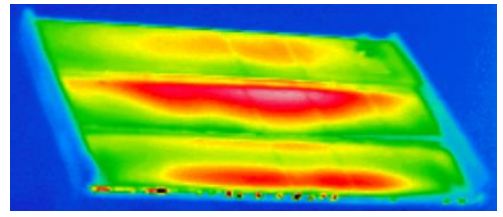

(e) Stepped PV- without gap

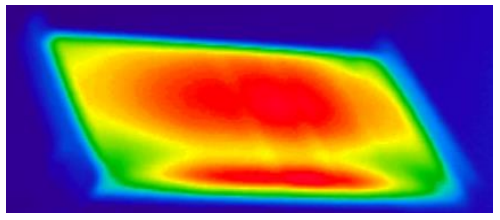

(g) Flat PV- without gap

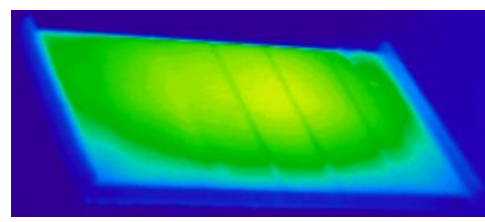

(i) Flat PV- gap $=20 \mathrm{~mm}$

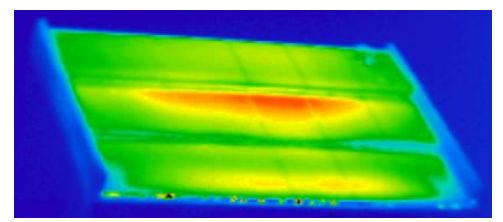

(k) Stepped PV- without gap

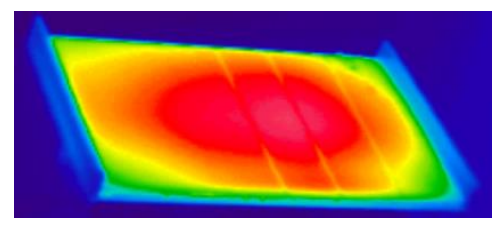

(m) Flat PV- without gap

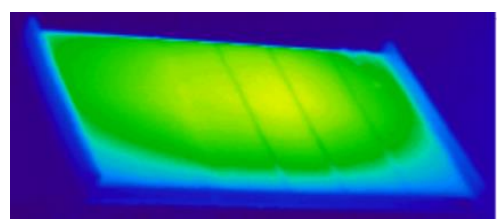

(o) Flat PV- gap $=20 \mathrm{~mm}$

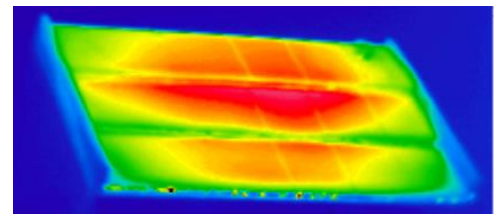

(q) Stepped PV- without gap

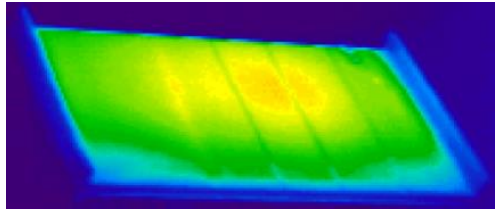

(b) Flat PV- gap= $10 \mathrm{~mm}$

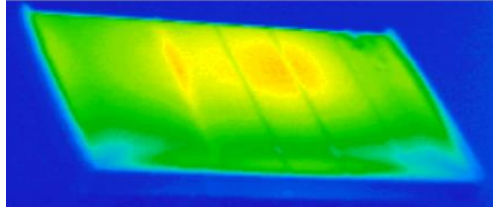

(d) Flat PV- gap $=30 \mathrm{~mm}$

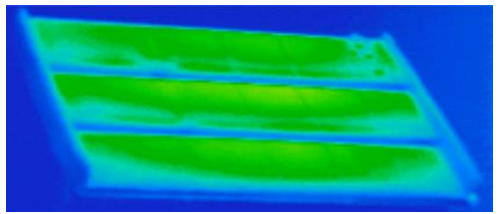

(f) Stepped PV- gap $=10 \mathrm{~mm}$

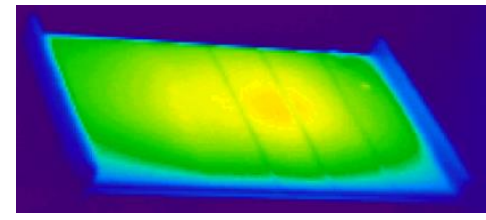

(h) Flat PV- gap $=10 \mathrm{~mm}$

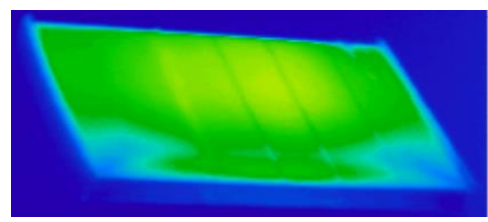

(j) Flat PV- gap $=30 \mathrm{~mm}$

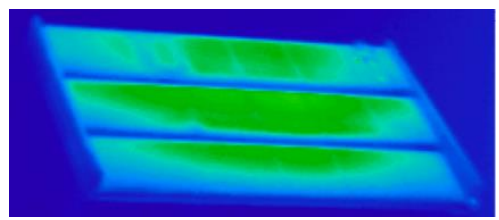

(l) Stepped PV-gap= $10 \mathrm{~mm}$

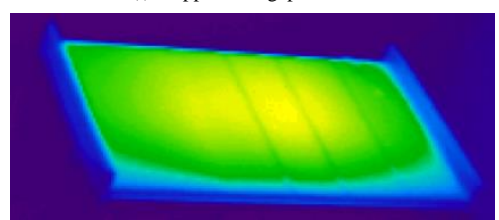

(n) Flat PV- gap= $10 \mathrm{~mm}$

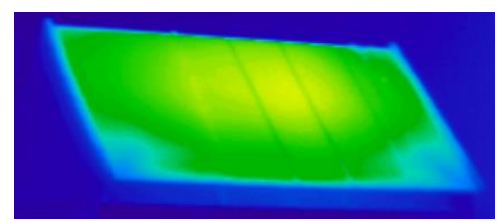

(p) Flat PV- gap $=30 \mathrm{~mm}$

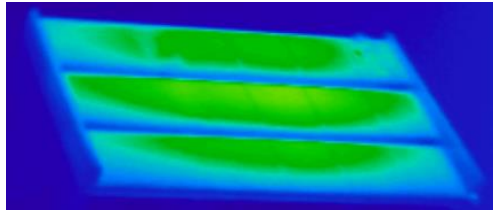

(r) Stepped PV- gap= $10 \mathrm{~mm}$

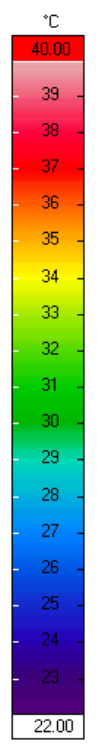

$2 \mathrm{~m} / \mathrm{s}$

$1 \mathrm{~m} / \mathrm{s}$

Figure 6. PV surface temperature, RI $=50 \frac{W}{m^{2}}$ (a-f) $U_{a}=2.0 \mathrm{~m} / \mathrm{s}(\mathrm{g}-1) U_{a}=1.0 \mathrm{~m} / \mathrm{s}(\mathrm{m}-\mathrm{r}) U_{a}=0.5 \mathrm{~m} / \mathrm{s}$ 


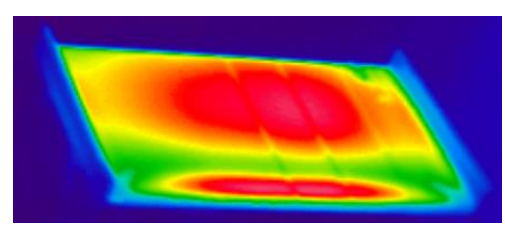

(a) Flat PV-without gap

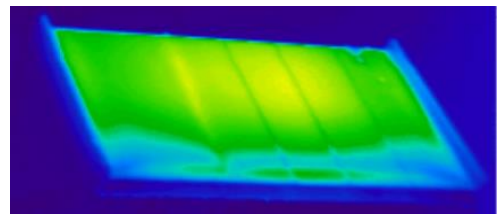

(c) Flat PV- gap $=20 \mathrm{~mm}$

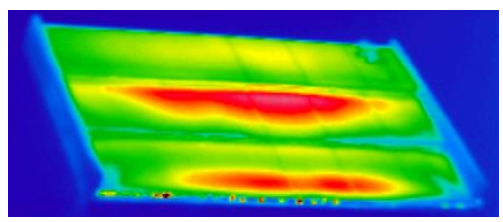

(e) Stepped PV- without gap

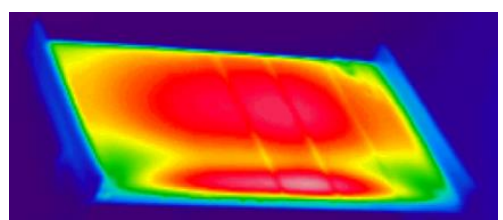

(g) Flat PV- without gap

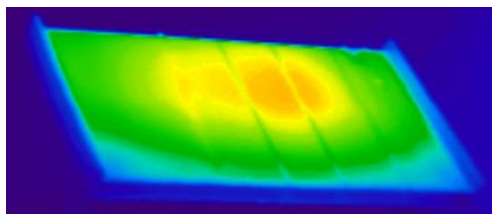

(i) Flat PV- gap $=20 \mathrm{~mm}$

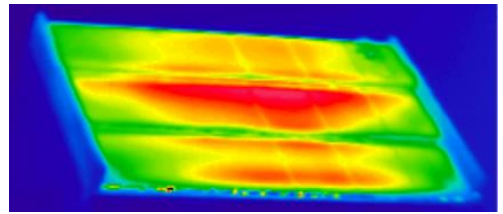

(k) Stepped PV- without gap

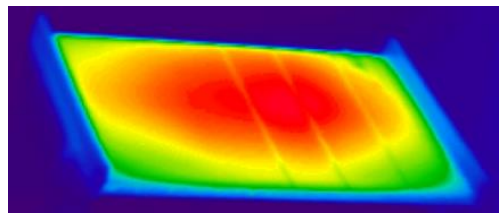

(m) Flat PV- without gap

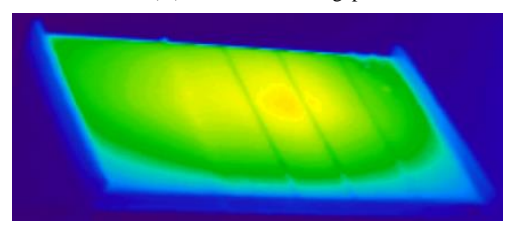

(o) Flat PV- gap $=20 \mathrm{~mm}$

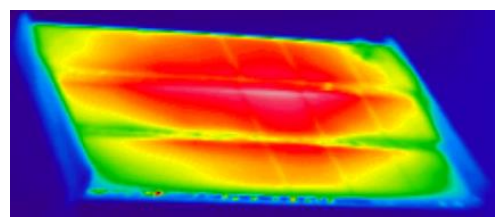

(q) Stepped PV- without gap

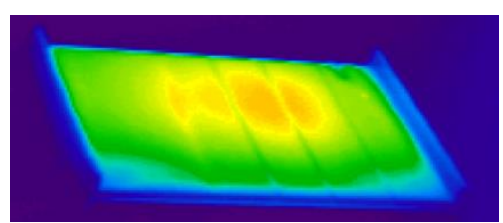

(b) Flat PV- gap $=10 \mathrm{~mm}$

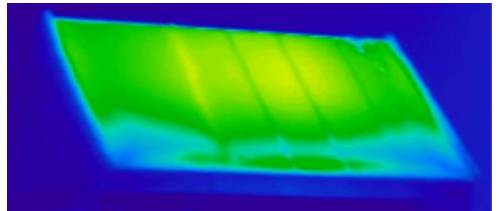

(d) Flat PV- gap $=30 \mathrm{~mm}$

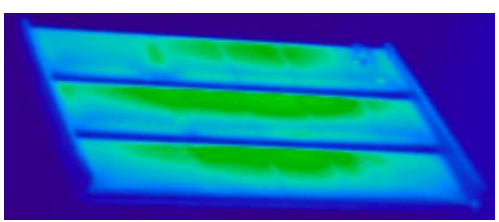

(f) Stepped PV- gap $=10 \mathrm{~mm}$

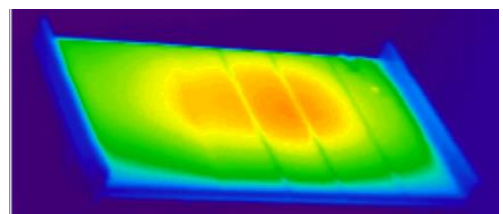

(h) Flat PV- gap $=10 \mathrm{~mm}$

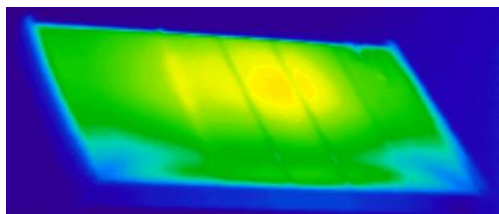

(j) Flat PV- gap= $30 \mathrm{~mm}$

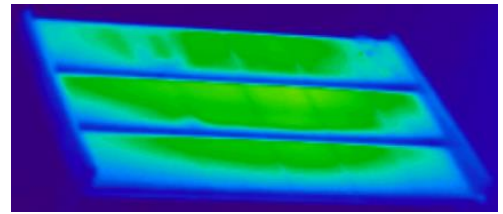

(l) Stepped PV- gap= $10 \mathrm{~mm}$

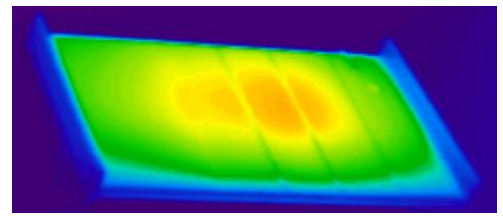

(n) Flat PV- gap $=10 \mathrm{~mm}$

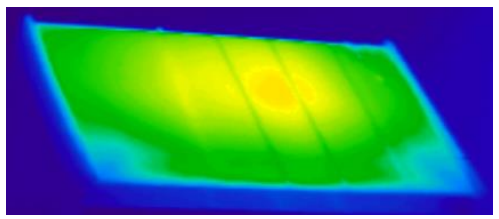

(p) Flat PV- gap $=30 \mathrm{~mm}$

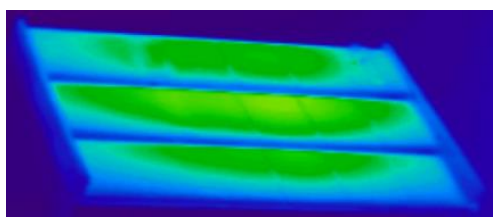

(r) Stepped PV- gap $=10 \mathrm{~mm}$

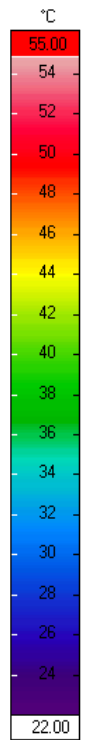

$2 \mathrm{~m} / \mathrm{s}$

Figure 7. PV surface temperature, RI $=100 \frac{W}{m^{2}}(\mathrm{a}-\mathrm{f}) U_{a}=2.0 \mathrm{~m} / \mathrm{s}\left(\mathrm{g}-1 U_{a}=1.0 \mathrm{~m} / \mathrm{s}(\mathrm{m}-\mathrm{r}) U_{a}=0.5 \mathrm{~m} / \mathrm{s}\right.$ 


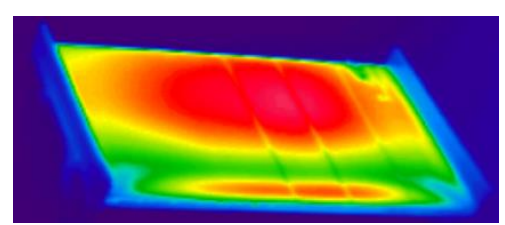

(a) Flat PV-without gap

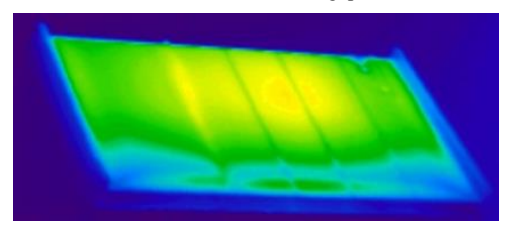

(c) Flat PV- gap $=20 \mathrm{~mm}$

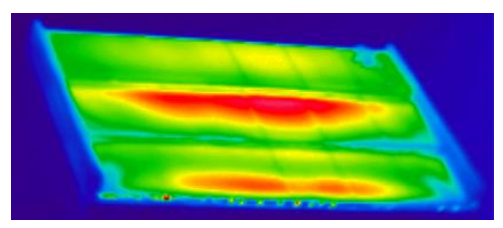

(e) Stepped PV- without gap

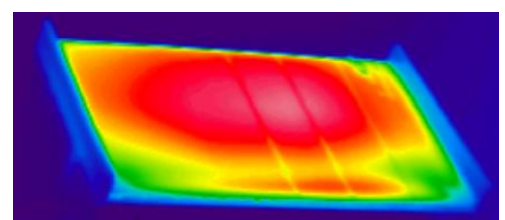

(g) Flat PV- without gap

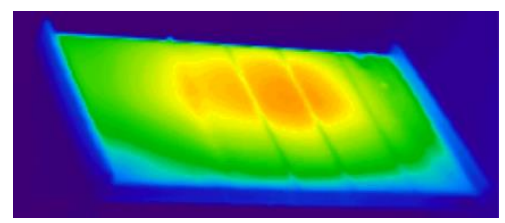

(i) Flat PV- gap $=20 \mathrm{~mm}$

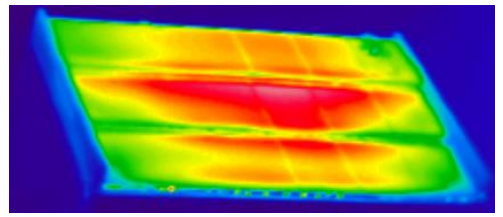

(k) Stepped PV- without gap

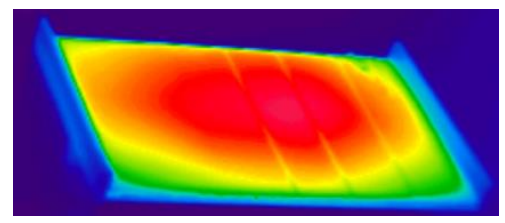

(m) Flat PV- without gap

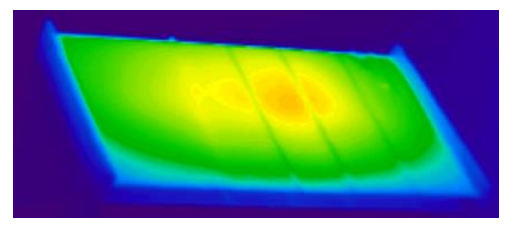

(o) Flat PV- gap $=20 \mathrm{~mm}$

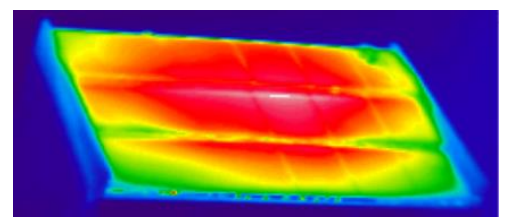

(q) Stepped PV- without gap

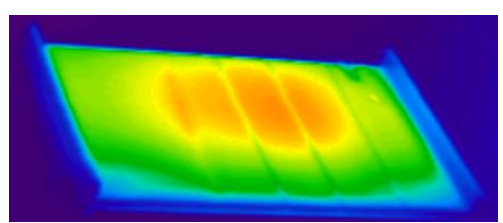

(b) Flat PV- gap $=10 \mathrm{~mm}$

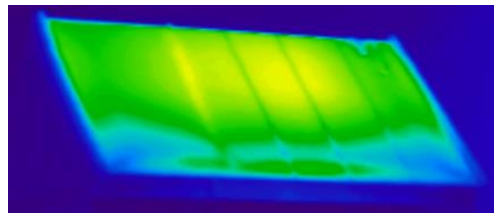

(d) Flat PV- gap $=30 \mathrm{~mm}$

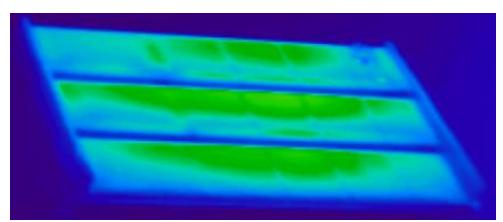

(f) Stepped PV- gap= $10 \mathrm{~mm}$

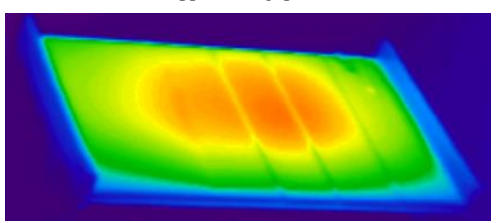

(h) Flat PV- gap= $10 \mathrm{~mm}$

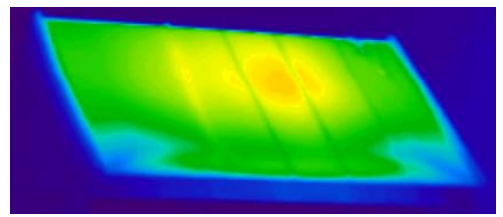

(j) Flat PV- gap $=30 \mathrm{~mm}$

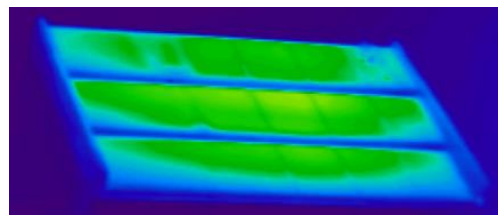

(l) Stepped PV- gap= $10 \mathrm{~mm}$

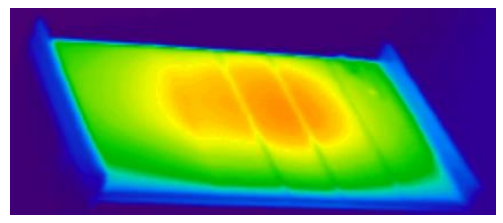

(n) Flat PV- gap $=10 \mathrm{~mm}$

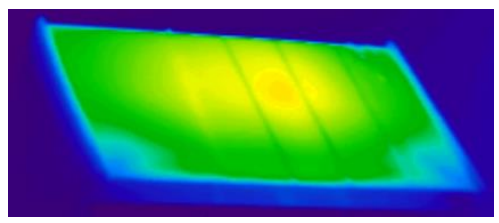

(p) Flat PV- gap $=30 \mathrm{~mm}$

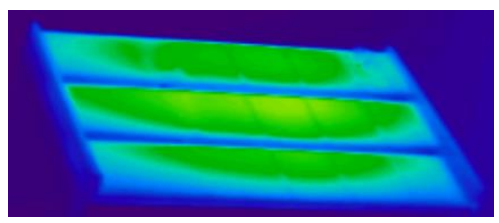

(r) Stepped PV- gap $=10 \mathrm{~mm}$

Figure 8. PV surface temperature, $\mathrm{RI}=200 \frac{W}{m^{2}}$, a-f) $U_{a}=2.0 \mathrm{~m} / \mathrm{s}\left(\mathrm{g}-1 U_{a}=1.0 \mathrm{~m} / \mathrm{s}(\mathrm{m}-\mathrm{f}) U_{a}=0.5 \mathrm{~m} / \mathrm{s}\right.$ 


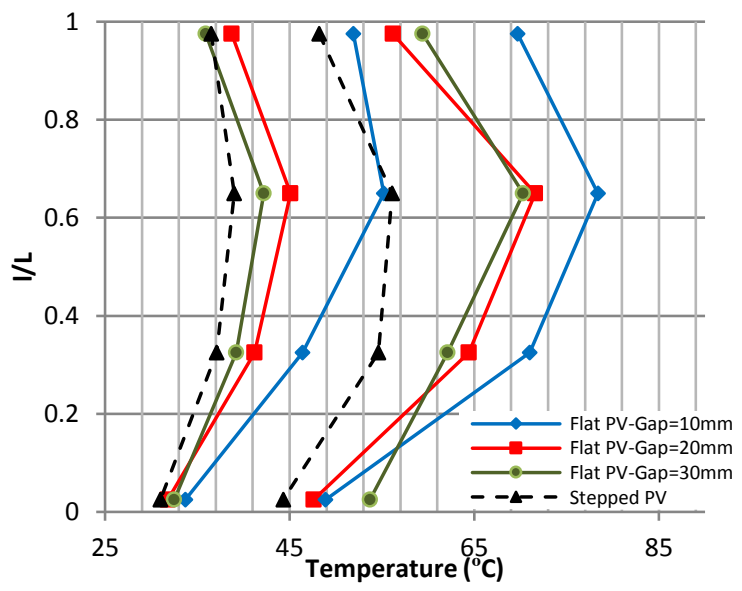

(a)

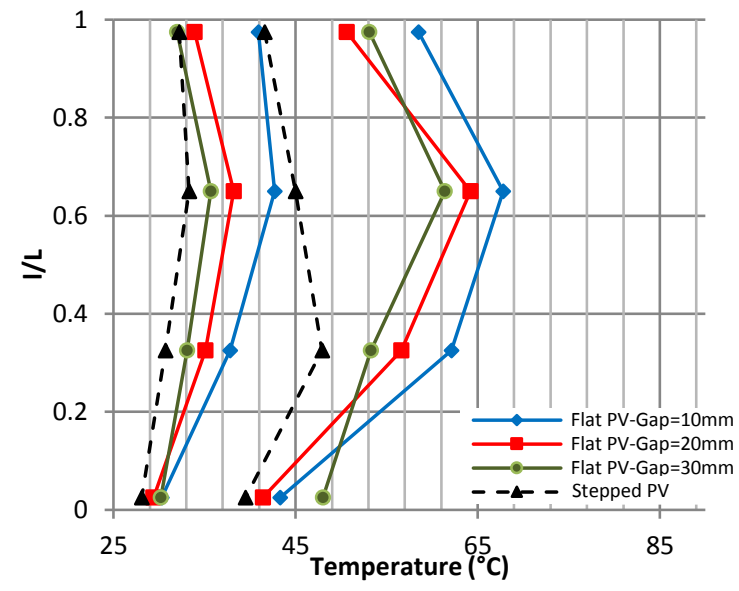

(b)

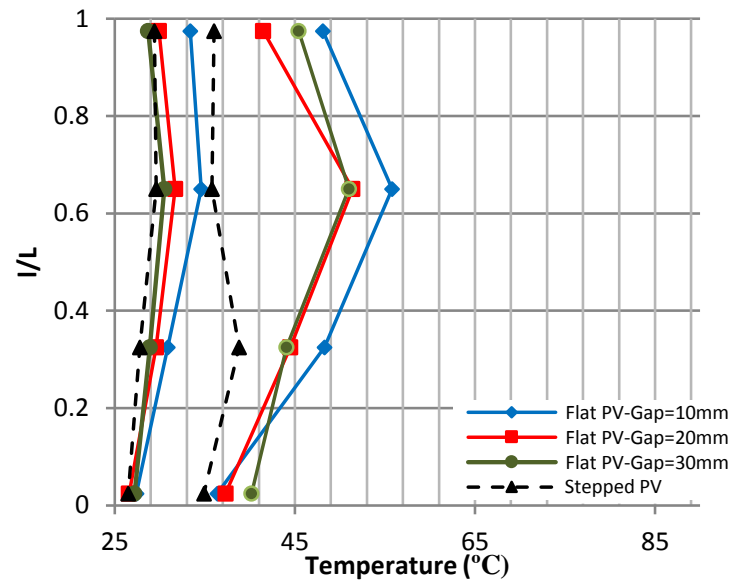

(c)

Figure 9. Cavity surface temperature (left: PV-side and right: roof-side), RI $=200 \frac{W}{m^{2}}$ (a) $U_{a}=0.5 \mathrm{~m} / \mathrm{s}$ (b) $U_{a}=$ $1.0 \mathrm{~m} / \mathrm{s}$ (c) $U_{a}=2.0 \mathrm{~m} / \mathrm{s}$ 